\title{
Bioseguridad en odontología frente COVID-19
}

\author{
Biosecurity in dentistry against COVID-19
}

Alcocer-Gamboa $\mathrm{A}^{1 \mathrm{a}}$, Vargas-Márquez $\mathrm{N}^{1 \mathrm{a}}$, Motallebi-Sotomayor $\mathrm{N}^{1 \mathrm{a}}$, Navas-Morales $\mathrm{G}^{1 \mathrm{a}}$, Carmen Li Pereyra ${ }^{1 \mathrm{~b}}$

\section{RESUMEN}

El artículo presenta diversas opciones de protección y consideraciones a tener en cuenta en la atención odontológica con el fin de prevenir y evitar riesgos de contagio.EI COVID-19 es el virus que según reportes de la OMS afecta a mayor cantidad de humanos en los últimos meses. Durante este tiempo, se han atendido emergencias y urgencias odontológicas que conllevan a revisar protocolos de bioseguridad mucho más estrictos. En el Perú ya se ha reiniciado la atención odontológica con protocolos de bioseguridad establecidos por el Ministerio de salud- MINSA, para una segura atención odontológica. El objetivo de este artículo es revisar diferentes protocolos y comparar opiniones de autores con respecto a las medidas que se deben de tomar en cuenta en esta nueva realidad para una óptima protección en la atención odontológica y para el control de la sanidad de los trabajadores y pacientes frente a una probable exposición al COVID-19.

Palabras clave: COVID-19; Protocolos Bioseguridad, Odontología. (Fuente: DeCS BIREME)

\section{ABSTRAC}

The article presents various protection options and considerations to take into account in dental care in order to prevent and avoid contagion risks. Covid-19 is the virus that according to WHO reports affects the largest number of humans in recent years. months. During this time, dental emergencies and emergencies have been attended that lead to reviewing much stricter biosafety protocols. In Peru, dental care has already been restarted with biosafety protocols established by the Ministry of Health-Minsa, for safe dental care. The objective of this article is to review different protocols and compare the opinions of authors regarding the measures that must be taken into account in this new reality for optimal protection in dental care and for the control of the health of workers and patients. against a probable exposure to covid19.

Key words: COVID-19; Biosafety Protocols, Dentistry. (Source: MeSH NLM)

${ }^{1}$ Universidad de San Martín de Porres. Lima, Perú.

Estudiante de pregrado

${ }^{\mathrm{b}}$ Doctora en Odontología, Coordinadora de Internado Estomatológico

Correspondencia:

Alessandra Nicole Alcocer Gamboa

Correo electrónico: alessa.nicole@hotmail.com

Dirección: Av. San Luis 1250, San Luis. Lima, Perú

Teléfono 5113464762

Citar como: Alcocer-Gamboa A, Vargas-Márquez N, Motallebi-Sotomayor N,Navas-Morales G, Carmen Li Pereyra. Bioseguridad en odontología frente COVID-19. KIRU. 2020; 18(4): 246-252. https://doi.org/10.24265/kiru.2020.v17n4.10 


\section{INTRODUCCION}

A inicios de este año se conoció a nivel mundial acerca de la nueva cepa de coronavirus causante del COVID 19, la Comisión Nacional de Salud en China informó que el COVID-19 formaría parte del grupo B de la clasificación de enfermedades infecciosas. Sin embargo, la forma de contagio de éste virus, y manejo clínico es semejante a las infecciones clasificadas en el grupo $A$, por lo que el protocolo a implementar en las clínicas dentales debe ser estricto ${ }^{(1)}$.

La Bioseguridad es un grupo de medidas y normas para salvaguardar la salud del personal de salud y pacientes frente a una atención brindada y reducir riesgos a la exposición de agentes : biológicos, químicos y físicos, los que se encuentran expuestos en el desarrollo de sus funciones y al medio ambiente ${ }^{(2)}$.

La atención Odontológica en los últimos meses se redujó, según recomendación, a procedimientos clínicos de emergencias (situaciones que presentan riesgo de muerte) o urgencias, preparando un protocolo para antes, durante y después de la atención ${ }^{(3)}$.

La selección de protección de bioseguridad a utilizar depende del grado de exposición, según el mecanismo de transmisión y del riesgo de la actividad a realizar ${ }^{(2)}$.

\section{MATERIALES Y MÉTODOS}

Para el presente articulo, se realizó una minunciosa búsqueda de información a través de la plataforma electrónica, siendo consultadas la base de datos, Pubmed, Scielo; BVS (Biblioteca virtual en salud), buscadores académicos tales como Google académico de las cuales se evaluaron aproximadamente 150 bibliografías considerándose los trabajos de idioma español, portugués e inglés, el término de búsqueda utilizado fue; marcado o etiquetado de covid-19 y bioseguridad en odontología.

Se incluyeron los artículos que describieron alguna técnica de marcaje o etiquetado de bioseguridad ante el covid19 que tuviera como finalidad el aporte en la atención odontología.

\section{Barreras físicas de Protección:}

El equipo de protección personal (EPP) es un grupo de elementos que se pueden llegar a utilizar por separado o en conjunto. Se le llama así porque puede evitar que el personal de salud se infecte o transmitan el virus al proteger sus vías respiratorias y piel del contacto directo ${ }^{(4)}$.

Para el dentista:

Según el MINSA 2020, recomienda el uso :

1. Mascarillas (preferentemente N95 o similares).

2. Guantes.

3. Mandilón descartable.

4. Mameluco u overol.

5. Gorro descartable.

6. Lentes de protección.

7. Protectores faciales.

Protocolo para colocar el Mandilón:

Según el MINSA 2020 debemos cubrir el torso desde el cuello hasta las rodillas y los brazos hasta las muñecas. Átela por atrás del cuello y la cintura $^{(2)}$.

\section{Protocolo para colocar el gorro:}

Recoger el cabello y sujételo si es necesario. Colóquese el gorro cubriendo completamente el cabello; si el gorro tuviese cintas, deberá atarse asegurando que el gorro no se caiga ${ }^{(2)}$.

\section{Protocolo para usar la mascarilla N95 o} similares:

Coloque las tiras a la altura de la mitad de la cabeza y en el cuello, debe ajustar y acomodar la banda flexible sobre la nariz y por debajo del mentón; verificar que se ajuste al rostro. Evitar tocar la máscara mientras la usa ${ }^{(2)}$.

\section{Protocolo para usar los lentes protectores:}

Los lentes no deben quedar sueltos.

Si no usan lentes protectores, colocarse el protector facial y ajustarlo en la parte posterior ${ }^{(2)}$.

\section{Protocolo para usar los guantes:}

Deben cubrir el puño del mandilón. Las manos no deben estar cerca del rostro; en caso se rompan o se encuentren muy contaminados deberán ser cambiados. Al terminar el tratamiento los guantes deberán ser desechados, no son reusables ${ }^{(2)}$.

Para el paciente:

1. Campo descartable.

2. Gafas de protección.

3. Gorro descartable.

Para el asistente:

1. Mascarillas (preferentemente N95 o similares).

2. Guantes.

3. Mandilón descartable. 
4. Gorro descartable.

5. Lentes de protección.

6. Protectores faciales.

El protocolo para colocar los elementos son iguales a los del dentista.

El potencial de transmisión a través de aerosoles salivales representa un peligro significativo para los odontólogos en la transmisión de COVID-19 ${ }^{(5)}$.

Los resultados de algunos estudios han demostrado que los aerosoles de patógenos altamente virulentos como el coronavirus pueden viajar más de 2 metros ${ }^{(6)}$.

El uso de enjuague bucal antes del tratamiento es uno de los métodos más eficaces para reducir la carga de microorganismos en los aerosoles orales. Un estudio mostró que el uso de enjuagues bucales antes del tratamiento, que incluyen clorhexidina ( $\mathrm{CHX})$, aceites esenciales y cloruro de cetilpiridinio (CPC), resultó en una reducción media del $68,4 \%$ de elementos formadoras de colonias en aerosoles dentales ${ }^{(6)}$.

El dique de goma proporciona una barrera de protección contra la fuente principal y prácticamente elimina todos los microorganismos que emergen de las secreciones respiratorias ${ }^{(6)}$.

Las gotas que contienen microorganismos infecciosos pueden depositarse en las superficies que están alrededor. Un análisis de 22 estudios reveló que el coronavirus pueden vivir en superficies inanimadas hasta por 9 días. Sin embargo, se pueden inactivar efectivamente desinfectando la superficie en un minuto. Estos desinfectantes de superficies contienen $62 \%-71 \%$ de etanol, $0.5 \%$ de peróxido de hidrógeno e $0.1 \%$ $(1 \mathrm{~g} / \mathrm{L})$ de hipoclorito de sodio ${ }^{(6)}$.

Es necesario aumentar las investigaciones en el control de aerosoles durante los tratamientos dentales, incluida la mejora en el diseño de consultorios dentales ${ }^{(7)}$.

El equipo de protección completo es de uso permanente en el espacio de atención odontológica y se deberá retirar antes de salir del consultorio y desecharlo en una bolsa roja.

El equipo de protección personal es obligatorio para la atención odontológica, además, el Servicio de Seguridad y Salud en el Trabajo deberá realizar una evaluación de riesgos para determinar si se deberán usar otros equipos de protección personal adicionales. Asimismo, las mascarillas N95 o similares, los trajes de protección biológica y los guantes, deben cumplir las normas asociadas a protección biológica, y la certificación correspondiente ${ }^{(2)}$.

El odontólogo no debe minimizar ninguna medida de protección para sus pacientes en estos

momentos de crisis; aunque la información es escasa con respecto a muchos temas del COVID-19, actualmente hay varios científicos demostrando la facilidad de trasmisión y su alto grado infeccioso ${ }^{(8)}$.

Debemos aplicar medidas de protección universales con un control efectivo de las infecciones. El uso de soluciones antimicrobianas ayudará a reducir la carga microbiana, así como la propagación de estas.

\section{Protocolos para la atención en el consultorio dental:}

A inicios del 2020, la Comisión Nacional de Salud en China informó que el COVID-19 entraría en el grupo B de la clasificación de enfermedades infecciosas, que incluye entre otras al SARS e influencia aviaria. Sin embargo, por la forma en la que este virus se contagia, lo recomendado es tratar a esta enfermedad de la misma manera en la que se trataron otras epidemias pasadas, tales como cólera y la plaga ${ }^{(1)}$.

Lo primero, y probablemente más importante para la atención en tiempos de pandemia, es realizar una correcta evaluación del estado de salud general del paciente. Esta evaluación la podemos realizar de dos maneras:

La primera y la más recomendada, sería a través de una previa video llamada con el paciente ${ }^{(9)}$. En esta video llamada, se puede identificar a un paciente posiblemente infectado, por un cuestionario de preguntas que se realiza.

- La segunda es evaluar al paciente cuando ingresa al consultorio.

Una vez haya pasado por los momentos de desinfección, se procede a tomarle la temperatura (debe ser menos o igual a 37 grados). A continuación se realizará la anamnesis mediante el cuestionario, en el cual se recomiendan incluir los siguientes puntos ${ }^{(1)}$ :

a) Presencia de fiebre, cansancio, conjuntivitis, sensación de ahogo, garganta sensible y/o dolor de cabeza presentes en las últimas dos semanas. 
b) Presencia de alguna deficiencia respiratoria, en la que se incluye tos seca, y/o dolor de pecho en las últimas dos semanas.

c) Contacto con personas que hayan tenido alguna deficiencia respiratoria en las últimas dos semanas.

d) Contacto con personas positivas al virus.

e) Viajes recientes o alguna relación con personas que hayan viajado recientemente (interior $y$ exterior del país) en los últimos 14 días.

El odontólogo deberá tomar la mejor decisión en base a las respuestas del cuestionario, y brindar atención a situaciones de emergencia y urgencia detalladas en la siguiente lista ${ }^{(3)}$. Según la OMS

\section{"Emergencias odontológicas (situaciones que} presentan riesgo de muerte) ${ }^{(10)}$ :

- Sangrados incontrolados;

- Celulitis e infecciones bacterianas difusas con edema y al1to riesgo a comprometer vías respiratorias;

- Traumatismos que involucren huesos faciales.

Urgencias odontológicas $^{(3)}$ :

- Dolor dental severo por inflamación de pulpar;

- Pericoronitis o dolor por tercera molar;

- Osteítis postoperatoria quirúrgica, cambios de apósito;

- Absceso o infección bacteriana localizada;

- Trauma dental con avulsión/luxación;

- Cementación definitiva de corona o puente si la restauración temporal se pierde, se rompe u ocasiona irritación gingival.

- Biopsia de tejido anormal;

- Lesión extensa por caries dental o restauraciones defectuosas que causan dolor;

- Retiro de suturas;

- Ajuste de prótesis dental en pacientes en tratamiento con radiación u oncológico;

- Ajustes o reparaciones de prótesis dental cuando la función este limitada o restringida;

- Reemplazo de restauraciones temporales en piezas con apertura cameral en pacientes con dolor;

- Corte o ajuste de aparatos de ortodoncia fijos que puedan estar perforando $u$ ocasionando una úlcera en la mucosa oral."

Posterior a la evaluación previa, la atención odontológica se realizará respetando los siguientes puntos ${ }^{1}$ : a) Desinfección de manos y suela de zapatos del paciente apenas ingresa al consultorio dental;

b) Lavado de manos del odontólogo, de la siguiente manera:

-Lavado de manos por 30 segundos con jabón.

-Secado de manos con toallas desechables.

-Usar gel desinfectante de base hidroalcohólica.

c) Enjuagues bucales preoperatorios;

d) Evitar en la medida de lo posible el uso de la jeringa triple;

e) Las radiografías intraorales y la toma de impresiones con alginato podrían estimular la secreción de saliva, la tos o el reflejo nauseoso;

f) Hacer uso del aislamiento absoluto junto al eyector para evitar en lo máximo posible la dispersión de fluidos corporales, tales como saliva y sangre, y agua;

g) De ser posible, en caso de endodoncias, posponer la obturación final hasta que el brote del virus se haya minimizado;

h) Evitar realizar cirugías, y en caso sea necesaria la sutura, se recomienda que sea reabsorbible.

Desinfección de los pacientes para la atención en el consultorio dental $^{(11)}$ :

Una vez que el paciente se ha presentado al consultorio dental ,se debe seguir un protocolo de desinfección que son los siguientes:

1. El personal que se encuentra en la recepción (protegido por las barreras físicas y manteniendo su distancia), debe abordar al paciente y tomarle la temperatura.

2. Indicarle al paciente pasar las plantas del calzado por un recipiente que se encuentra en la puerta de entrada al consultorio. Este recipiente debe tener un trapo embebido en con $\mathrm{NaOCl}(10 \mathrm{~mL}$ de solución/1,000 $\mathrm{mL}$ de $\mathrm{H} 2 \mathrm{O}$ ) para desinfectar, luego le roseara por lados del cuerpo alcohol (>70\%).

3. Se le dará al paciente unas botas desechables para que pueda pasar

4. El personal le aplicara alcohol gel en la mano del del paciente y si en caso el paciente presenta algún objeto como celular, aretes, collar, reloj se le dirá que lo guarde.

5. Seguido se le indicara que se lave las manos para luego la colocación de guantes.

Se debe considerar, como medida de prevención, que todo paciente que ingrese al consultorio dental puede ser un portador del COVID 19. 
Los enjuagatorios bucales son un procedimiento necesario y eficaz para reducir la carga de microorganismos orales ${ }^{(12)}$. Por lo tanto, es recomendable indicar al paciente que antes del procedimiento odontológico se enjuague la cavidad bucal por un minuto. Con soluciones como la povidona al $0,2 \%$, con peróxido de hidrógeno al $0,5 \%$ o con cloruro cetilpiridino (CPC) al $0,05 \%{ }^{(13)}$.

El uso del CPC, es recomendado en base a investigaciones favorables sobre su acción frente al covid-19. Este compuesto de amonio cuaternario es considerado como un antiséptico de alto espectro, siendo muy activo contra bacterias gram positivas, gram negativas, hongos y virus. Un estudio reciente de Li Zhiyong, encontró al CPC muy eficaz contra el coronavirus SARS-CoV-2 y sugiere usar este componente como preoperatorio para reducir la carga viral ${ }^{(14)}$.

$\begin{array}{lll}\text { Desinfección }_{\text {instrumentos }^{(13)}} \text { : y } & & \text { Esterilización de }\end{array}$

Cabe recalcar que las personas que realizan la desinfección y esterilización de los instrumentos deben estar protegido con todas las barreras físicas de protección mencionados.

Los pasos para una descontaminación y esterilización adecuada deben ser:

1. Limpieza y desinfección: comienza con agua y detergente enzimático para eliminar por arrastre materias orgánicas y reduce la cantidad de carga bacteriana.

2. Empaquetado de los instrumentos en caso si se va usar autoclave.

3. Esterilización: se va dar de 2 formas:

- Autoclave (calor húmedo): con una temperatura de $121^{\circ} \mathrm{C}$ por 15 minutos.

- Estufa (calor seco): con una temperatura de $170^{\circ} \mathrm{C}$ por $60 \mathrm{~min}$

Por último, se almacenará en un ambiente cerrado para evitar una contaminación.

Por otro lado, estudios recientes indicaron que el virus puede permanecer de 4 a más de 24 horas en el cobre y el papel, 48 horas en acero y 72 horas para el plástico ${ }^{(15)}$. La acción a tomar seria la desinfección en todo material del consultorio (Unidad dental, mesas, sillas, muebles, etc.) con un propósito de inactivar y eliminar el virus por los desinfectantes como el alcohol etílico al $70 \%$ y el hipoclorito de sodio al $0,1 \%$ durante al menos 1 minuto $^{(16)}$. Según la OMS 2020 es recomendable una concentración de $0,1 \%$ o 1000 ppm (1 parte de lejía de uso doméstico al $5 \%$ por cada 49 partes de agua) ${ }^{(17,18)}$.

\section{DISCUSIÓN}

Diversos autores mencionan la necesidad de reforzar las medidas de bioseguridad en este contexto de la pandemia; para ello han propuesto protocolos similares para la atención odontológica, si bien es cierto estos son de gran ayuda para prevenir y controlar la propagación de este virus, se debe considerar implementar medidas adicionales en el tratamiento ${ }^{(2,3,18)}$.

En un estudio de Montalli V, et al. Elaboran una barrera de protección individual que consistía en una capa de película de PVC combinada con una capa de polipropileno montada en un marco, este demostró ser eficaz en reducir la dispersión de gotas y los aerosoles que produce la turbina de alta velocidad comparada sin la asociación de esta; resultando en una opción viable para optimizar la bioseguridad en el entorno dental ${ }^{(19)}$.

Sigua E, et al. "Menciona que, si se opta por la reutilización de respiradores $\mathrm{N} 95$, este se debe limitar en su uso como máximo de 3-5 veces; ya que en varias investigaciones se demostró que al someterlos a un proceso de desinfección o esterilización producen una degradación del filtro de manera significativa y en los niveles de penetración de partículas, no alcanzando los niveles de aprobación por el NIOSH"(20).

Por último, en el estudio de Amorim $L$, et al. "Recomienda el uso de peróxido de hidrógeno al $1 \%$ a través del enjuague bucal debido a su potencial oxidativo y reducción de la carga viral de COVID-19 comparado con el digluconato de clorhexidina al $0,12 \%$ ya que aún carece de evidencia científica más sólida" ${ }^{(21)}$.

\section{CONCLUSIÓN}

Todas las atenciones odontológicas a ser realizadas deben seguir el protocolo de bioseguridad con la finalidad reducir la probabilidad de contagio de Covid-19 brindándole mayor seguridad al personal clínico y a los pacientes.

Se recomienda el seguimiento del cumplimiento de estas medidas de bioseguridad por la entidad de salud correspondiente. 
Contribución de autoría: AAG, NNV, NMS, GNM, HJC y CLP participaron en la recolección y análisis de datos, redacción y aprobación de la versión final del manuscrito.

Fuentes de financiamiento: autofinanciada.

Conflicto de Interés: Los autores declaran no tener conflicto de interés

\section{REFERENCIAS}

1. Bermúdez-Jiménez C, Gaitán-Fonseca C, Aguilera-Galaviz L. Manejo del paciente en atención odontológica y bioseguridad del personal durante el brote de coronavirus SARS-CoV-2 (COVID-19). Rev ADM.2020;77(2):88-95. doi:10.35366/93101

2. Ministerio de Salud. Manejo de la atención estomatologica en el contexto de la pandemia por COVID-19. MINSA. Lima- Perú. 2020

3. Franco JB., De Camargo A. y Peres M. Cuidados Odontológicos na era do COVID-19: recomendações para procedimentos odontológicos e profissionais. Rev Assoc Paul Cir Dent. 2020; 74(1): 18-21.

4. Morales Navarro D. Acciones del personal de salud del área estomatológica en relación al COVID-19. Rev Cubana Estomatol [Internet]. 2020 [citado 18 jul 2020]; 57(1):[aprox. 0 p.]. Disponible

en: http://www.revestomatologia.sld.cu/index.p $\mathrm{hp} / \mathrm{est} / \mathrm{article} / \mathrm{view} / 3245$

5. Han P, Ivanovski S. Saliva-Friend and Foe in the COVID-19 Outbreak. Diagnostics (Basel). 2020;10(5):290. Published 2020 May 9 doi:10.3390/diagnostics10050290

6. Ge ZY, Yang LM, Xia JJ, Fu XH, Zhang YZ. Possible aerosol transmission of COVID-19 and special precautions in dentistry. J Zhejiang Univ Sci B. 2020 May;21(5):361-368. doi: 10.1631/jzus. B2010010. Epub 2020 Mar 16. PMID: 32425001; PMCID: PMC7089481

7. Villani FA, Aiuto R, Paglia L, Re D. COVID-19 and Dentistry: Prevention in Dental Practice, a Literature Review. Int J Environ Res Public Health. $2020 \quad$ Jun 26;17(12):4609.Doi:10.3390/ijerph17124609. PMID: 32604906; PMCID: PMC7344885.

8. Sigua $E$, Bernal J, Lanata $A$, Sánchez $C$, Rodríguez J, Haidar Z, et al . COVID-19 y la Odontología: una Revisión de las Recomendaciones y Perspectivas para Latinoamérica. Int. J. Odontostomat. [Internet]. 2020 Sep; 14(3): 299-309. Disponible en: https://scielo.conicyt.ci/ scielo.php?script=sci_arttext\&pid=S0718381X2020000300299\&lng=es.

9. Ramirez, V. C. Enfermerdad por coronavirus 2019(COVID-19) y su repercusión en la consulta odontológica: una revisión. 2020; 23(2): 139-146.

10. Meng L., Hua F. y Bian Z. Coronavirus disease 2019 (COVID-19): emerging and future challenges for dental and oral medicine. Journal of Dental Research. 2020 may;99(5): 481-487.

11. Araya, S. C. Consideraciones para la atención de urgencia odontológica y medidas preventivas para COVID-19 (SARSCoV2). 2020;14(3):268-270.

12. Maquera K, Villanueva C, J. U. L. Efectividad de enjuagues bucales en el tratamiento dental durante la pandemia COVID-19. Revista Odontológica Basadrina. 2020; 4(1), 48-53.

13. To, K. K.-W. et al. Consistent detection of 2019 novel coronavirus in saliva. Clin. Infect. Diseases. 2020 https://doi.org/10.1093/cid/ciaa149.

14. Basso, M., Bordini, G., Bianchi, F., Prosper, L., Testori, T., \& Del Fabbro, M. (2020). Utilizzo di collutori preoperativi contro il virus SARS-CoV2 (COVID-19): revisione della letteratura e raccomandazioni cliniche. Quintessenze Internazionale.2020;1.

15. Doremalen $\mathrm{N}$. et al. Aerosol and Surface Stability of SARS-CoV-2 as Compared with SARS-CoV-1. The New England Journal of Medicine. March 23, 2020.Disponible en: https://www.nejm.org/doi/full/10.1056/NEJMc2 004973

16. G. Kampf, D. Todt, S. Pfaender, E. Steinmann. Persistence of coronaviruses on inanimate surfaces and their inactivation with biocidal agents .Journal of Hospital Infection.2020; 104 246e251.Disponible en: https://www.journalofhospitalinfection.com/artic le/S0195-6701(20)30046-3/fulltext

17. Organización Mundial de la Salud. Limpieza y Desinfección de Superficies del Entorno Inmediato en el contexto de la COVID19.OMS; 16 Mayo 2020. [Consultado 18 jul 2020].Disponible en: https://n9.cl/uzt4

18. Guiñez, C. M. Impacto del COVID-19 (SARSCoV-2) a nivel mundial, implicancias y medidas preventivas en la práctica dental y sus consecuencias psicológicas en los pacientes. 2020;14(3):271- 278.

19. Ather A, Patel B, Ruparel NB, Diogenes A, Hargreaves KM. Coronavirus Disease 19 (COVID-19): Implications for Clinical Dental Care. J Endod. 2020;46(5):584-595.

20. Montalli V, Garcez A, Montalli G, França F, Suzuki S, Mian L, et al. Individual biosafety barrier in dentistry: an alternative in times of covid-19. Preliminary study. RGO, Rev. Gaúch. Odontol. [Internet]. 2020; 68: e20200088. Disponible en: http://www.scielo.br/scielo.php?script=sci artte xt\&pid=S1981-86372020000100308\&Ing=en.

21. Amorim LM, Maske TT, Ferreira SH, Santos RB, Feldens CA, Kramer PF. New postCOVID-19 biosafety protocols in pediatric dentistry. Pesqui Bras Odontopediatria Clín Integr. 2020; 20(supp1):e0117. Disponible en: ttps://doi.org/10.1590/pboci.2020.117 
Alessandra Alcocer Gamboa alessa.nicole@hotmail.com

Naomi Nicoll Vargas Marquez. naominvm16@gmail.com

Nilufar Motallebi Sotomayor. nilu1998@hotmail.com

Gennaro Gastón Navas Morales. gennaro_navas@usmp.pe

Héctor Joaquín Jerónimo Cabezas. joaquino_o@hotmail.com

Carmen Li Pereyra

clip@usmp.pe
(D) http://orcid.org/0000-0003-0760-0829

(b) http://orcid.org/0000-0003-4203-5271

(1) http://orcid.org/0000-0002-0750-1735

(b) http://orcid.org/ 0000-0003-4897-1108

(D) http://orcid.org/0000-0002-1951-9115

(D) http://orcid.org/ /0000-0003-2792-7327 